\title{
Probability learning In rats reinforced with brain stimulation'
}

ROGER N. JOHNSON, Tufts University, Medford, Mass. 02155, and RONALD S. LEVY, Amherst College, Amherst, Mass. 01002

Eight rats were given massive training sessions with spatial probability problems. A noncorrection procedure was used and brain stimulation served as the reinforcer. Results indicate no clear response strategy with only one rat showing clear and consistent maximizing.

Behavioral comparisons of different species in probability learning problems have produced performance strategies which some experimenters (Bitterman, 1965a) attribute to qualitative differences along the phylogenetic scale. For example, Bitterman reports that on visual and spatial probability problems, rats tend to maximize or approach the more frequently rewarded stimulus on nearly every trial, while fish generally match their responses to the reinforcement probabilities.

Recently, such generalizations have been questioned (Mackintosh, 1967; Poland \& Warren, 1968) particularly when animals are run for an extended number of trials. The purpose of the present experiment is to test the generality of maximizing behavior in rats run for large numbers of trials in situations usually producing clear maximizing. The use of intracranial stimulation (ICS) provides an efficient procedure for accomplishing this goal (Johnson, 1966; Johnson \& Levy, 1968).

SUBJECTS AND APPARATUS

Eight male Charles River strain albino rats were used. Rats 203,207 , and 217 were about 100 days old while the other Ss were about 300 days old. All Ss had previous experience pressing a single lever for ICS. Animals were maintained on an ad lib diet of Purina Lab Chow. The apparatus is shown in Fig. 1 and is similar in operation to one described elsewhere (Johnson, 1968).

ELECTRODE IMPLANTATION AND HISTOLOGY

Subjects were stereotaxically implanted with bipolar electrodes .014 in. in diam (Plastic Products Co.). Following the experiment, Ss were perfused and brain sections were stained with cresyl violet. Electrode tips were found to be distributed in the lateral hypothalamus and adjacent medial forebrain bundle.

\section{PROCEDURE}

In pretraining, Ss were shaped to press either response panel for ICS on a CRF schedule. After several hundred trials Ss were shifted directly to the probability conditions which were determined by a 60-step Actan programmer. Reinforcement consisted of $0.5 \mathrm{sec}$ of sine wave current stepped down with a Variac and presented via a mercury swivel. A noncorrection procedure was used in which any response would deactivate both panels for an intertrial interval of $5 \mathrm{sec}$. The number of responses on both panels was printed out every 25 trials. Each $S$ was run for a number of daily sessions until the electrode was removed or the animal stopped responding. The total number of trials for each $S$ can be determined from Fig 2 . The probabilities employed for each rat as well as the points where probabilities were changed can also be determined from Fig. 2.

\section{RESULTS AND DISCUSSION}

It can be seen from Fig. 2 that no single response strategy characterizes the behavior of all eight Ss. Only Rat 207 consistently maximized, although Rat 203 also maximized much of the time. Most of the Ss shifted their response strategies a number of times in what appeared to be an unsystematic fashion. Rat 19 , however, continued to respond to the $60 \%$ reinforced side about $85 \%$ of the time for nearly 8000 trials. In general, neither matching nor maximizing would describe the behavior of most of the animals, but rather, they seemed to respond at a level somewhere between the two. As a group, Ss responded $86 \%$ of the time to the more frequently rewarded side in the $60-40$ problem. It can be noted that when the probabilities are changed, Ss quickly modify their behavior. For example, when Rat 50 was switched from a $60-40$ problem to a $40-60$ problem after 1600 trials, his responses to the left side dropped sharply.

It is difficult to account for the unusual findings of this experiment. Previous research (Bitterman, Wodinsky, \&

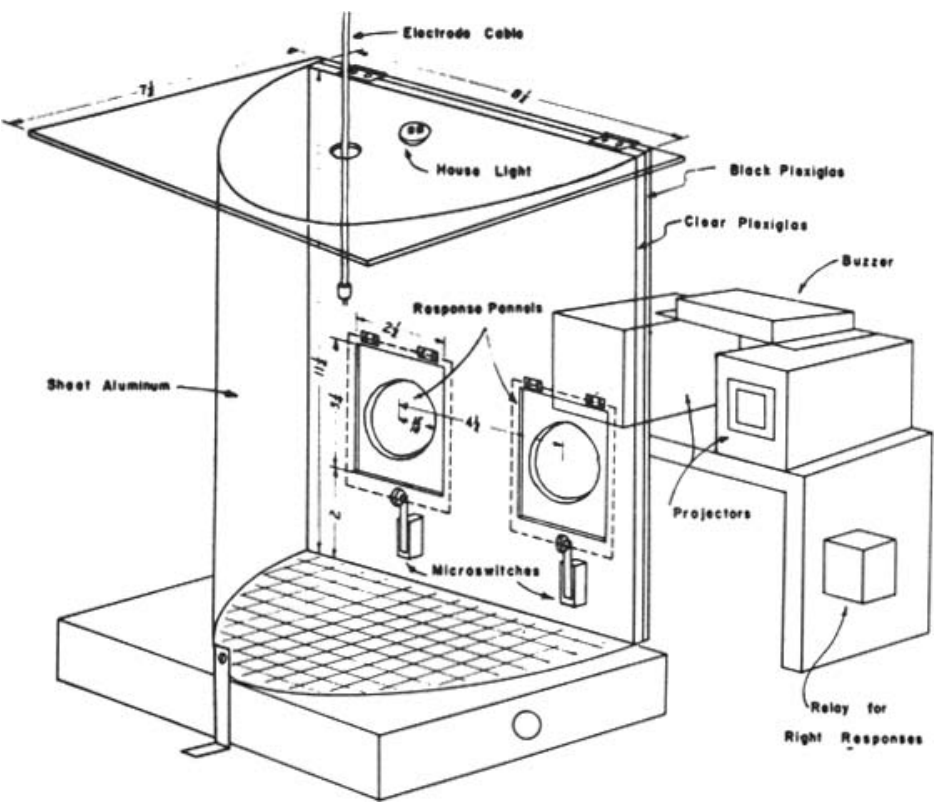

Fig. 1. Schematic view of the two-choice discrimination apparatus. 


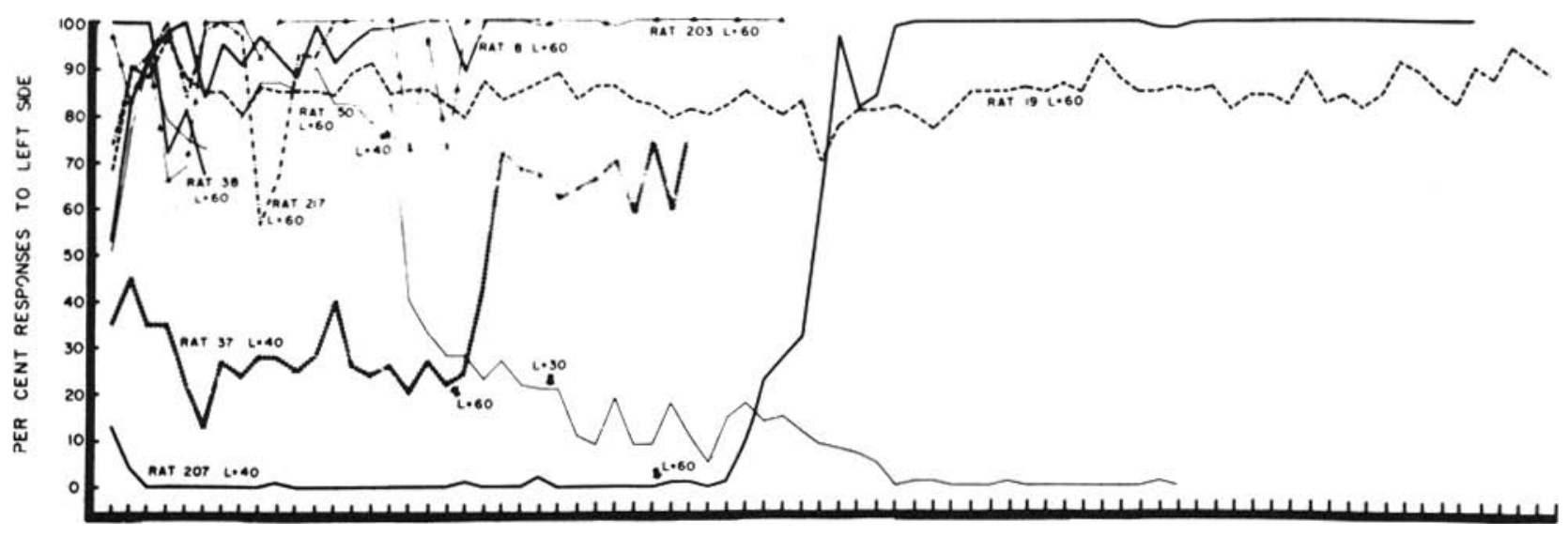

\section{BLOCKS OF TRIALS}

Fig. 2. Per cent responses to the left side over blocks of 100 trials for each animal. The probabilities employed for each animal can be determined with reference to the left side. For example, $L=40$ indicates that left responses are reinforced $40 \%$ of the time and the right responses $60 \%$. The points where probabilities were changed are indicated by a black arrow accompanied by the new probability.

Candland, 1958; Roberts, 1966) showed that maximizing behavior is increased by the use of spatial discriminations (about $91 \%$ of all responses to the more frequently rewarded side in a $60-40$ problem in the Bitterman et al experiment, and nearly $100 \%$ maximizing in a $70-30$ problem in the Roberts experiment). Furthermore, the use of a noncorrection procedure has also been shown to increase maximizing (Bitterman, Wodinsky, \& Candland, 1958; Parducci \& Polt, 1958; Uhl, 1963; Poland \& Warren, 1967). In the Poland \& Warren (1967) experiment, for example, cats maximized about $98 \%$ in a $60-40$ spatial problem when a noncorrection procedure was used. More generally, Bitterman (1965b) has stated that without a guidance procedure, all species tend to maximize. It is difficult to understand how the use of brain stimulation or a massed trial procedure might explain the behavior obtained in the present experiment. In any case, the generalization that all species tend to maximize in a spatial probability problem using a noncorrection procedure appears to need some qualification.

\section{REFERENCES}

BITTERMaN, M. E. Phyletic differences in learning. American Psychologist, 1965a, 20, 396-410.

BITTERMAN, M. E. The evolution of intelligence. Scientific American, $1965 \mathrm{~b}, 212,92-100$.

BITTERMAN, M. E., WODINSKY, J., \& CANDLAND, D. K. Some comparative psychology. American Journal of Psychology, 1958, 71, 94-110.
JOHNSON, R. N. Pattern discrimination learning set formation in rats with brain stimulation as a reinforcer. Psychonomic Science, 1966, 6, 315-316.

JOHNSON, R. N., \& LEVY, R. S. Oddity learning in rats reinforced with brain stimulation. Psychonomic Science, 1968, 12, 95-96.

JOHNSON, R. N. Effects of intracranial reinforcement intensity and distributional variables on brightness reversal learning in rats. Journal of Comparative \& Physiological Psychology, 1968, 66, 422-426.

MACKINTOSH, N. J. Comparative psychology of reversal and probability learning. Paper presented at meetings of the Experimental Analysis of Behaviour Group, Brighton, England, April 6, 1967.

PARDUCCI, A., \& POLT, J. Correction vs noncorrection with changing reinforcement schedules. Joumal of Comparative \& Physiological Psychology, 1958, 51, 492-495.

POLAND, S. F., \& WARREN, J. M. Spatial probability learning by cats. Psychonomic Science, 1967, 8, 487-48.

POLAND, S. F., \& WARREN, J. M. Cats' performance on visual probability learning problems after prolonged training. Journal of Comparative \& Physiological Psychology, 1968, 65, 545-546.

ROBERTS, W. A. Learning and motivation in the immature rat American Journal of Psychology, 1966, 79, 3-23.

UHL, C. N. Two-choice probability learning in the rat as a function of incentive, probability of reinforcement, and training procedure. Journal of Experimental Psychology, 1963, 66, 443-449.

NOTE

1. This research was supported by Grant MH16147-01 of the National Institutes of Health, United States Public Health Service. 